\title{
Combination of Oral Tranexamic Acid with Topical 3\% Tranexamic Acid versus Oral Tranexamic Acid with Topical 20\% Azelaic Acid in the Treatment of Melasma
}

\author{
Fahmida Malik1, Malik Muhammad Hanif1 and Ghulam Mustafa²
}

\begin{abstract}
Objective: To compare the effect of combination therapies of topical $3 \%$ tranexamic acid versus topical $20 \%$ azelaic acid each combined with oral tranexamic acid in the treatment of melasma.

Study Design: Interventional comparative study.

Place and Duration of Study: Department of Dermatology, Sheikh Zayed Hospital, Rahim Yar Khan, from July 2017 to June 2018.

Methodology: Cases of melasma diagnosed clinically (based upon history and the clinical findings of symmetrically distributed hyperpigmented macules and patches on the face), aged 12 to 50 years, were selected. The cases were divided into two groups by simple random sampling method. The cases in group A were treated by oral tranexamic acid (250 mg twice daily) with topical 3\% tranexamic acid (twice daily). In group B, cases had oral tranexamic acid (250 mg twice daily) with topical $20 \%$ azelaic acid (daily) for six months. They were followed every second month upto 6 months and the efficacy was assessed on the basis of scores on MASI scale.

Results: In 100 patient, there was no significant difference in terms of mean MASI score at 2 and 4 months with p-value of 0.20 and 0.89 , respectively. However, mean MASI score was significantly less in group A (6.06 \pm 5.06 vs. $10.62 \pm 7.43$ ) in group B ( $\mathrm{p}=0.001)$. In group A, $14(28 \%)$ had excellent response, whereas in group B, $11(22 \%)$ had excellent results. Conclusion: Combination of oral and topical $3 \%$ tranexamic acid is significantly better than oral tranexamic acid with $20 \%$ azelaic acid for treatment of melasma.
\end{abstract}

Key Words: Melasma, Tranexamic acid, Azelaic acid.

\section{INTRODUCTION}

Melasma is an acquired hyperpigmentation of the skin that typically affects the sun-exposed areas of the face. It is most common in women with darker complexions, who live in areas of intense ultraviolet (UV) radiation exposure.1,2 Melasma causes considerable cosmetic disfigurement and psychological distress; quality-of-life studies have shown a significant negative effect of melasma on emotional wellbeing, social life, and leisure activities.3,4 The prevalence of melasma is reported around the globe. In Brazil, it is about $5-9 \%$, which remains main cause of demand for dermatological care in Saudia Arabia, Nepal and Brazil. 3-5 The pathogenesis of melasma is poorly understood. Contributing factors include darker skin phototype (especially III and IV), ultraviolet (UV) radiation, hormonal factors (eg, pregnancy, oral contraceptives), genetic predisposition, cosmetic use, thyroid dysfunction, and antiepileptic medications. 5,6

Department of Dermatologyl / Community Medicine2,

Sheikh Zayed Medical College and Hospital, Rahim Yar Khan, Pakistan

Correspondence: Dr. Fahmida Malik, Department of Dermatology, Sheikh Zayed Medical College and Hospital, Rahim Yar Khan,

Pakistan

E-mail:fahmidamalik77@gmail.com

Received: July 13, 2018; Accepted: January 29, 2019
The diagnosis of melasma is based upon history and the clinical finding of symmetrically distributed hyperpigmented macules and patches on the face.7,8 Examination under Wood's light may be helpful in identifying the pattern of pigment deposition.9-11 The melasma area and severity index (MASI) was created in an attempt to standardise the subjective evaluation of melasma in clinical trials. 4,5

The treatment of melasma can be challenging because of its chronic and relapsing nature.12-14 Treatments include skin-lightening agents, chemical peels, and laser and light-based therapy. ${ }^{15-18}$

These include hydroquinone used in strength of $2 \%$ and $4 \%$, azelaic acid $15 \%$ and $20 \%$, mequinol, kojic acid, topical retionids $0.25 \%, 0.5 \%$ and $0.1 \%$. All of these treatment options result in excellent cure rate among $60 \%$ to $90 \%$. ${ }^{19-22}$ Several types of lasers have been used for the treatment of melasma with variable results. 4 Oral and topical tranexamic acid has been used recently in the treatment of melasma. $4,5,11-13$

Tranexamic acid is a plasmin inhibitor and lysine analogue that has been shown to inhibit UV-induced pigmentation in animal models while azelaic acid is a naturally occurring, nonphenolic, nine-carbon dicarboxylic acid that competitively inhibits tyrosinase. Both have shown variable results for its efficacy in melasma. ${ }^{11,13}$ 
This study was planned to assess the effects of combination therapy in melasma. The objective of this study was to compare the effect of combination therapies of oral tranexamic acid with topical $3 \%$ tranexamic acid versus oral tranexamic acid with topical $20 \%$ azelaic acid in the treatment of melasma.

\section{METHODOLOGY}

This was an interventional comparative study, conducted from July 2017 to June 2018 at Department of Dermatology, Sheikh Zayed Hospital, Rahim Yar Khan. Sample size was calculated by taking $95 \%$ confidence interval power of study $80 \%$ and cure rate in azelaic acid group taken as 65\%; whereas, cure rate in Tranexamic acid group taken as $90 \% .16,17$

Cases were taken in the range of 12 to 50 years of either gender of melasma diagnosed clinically based upon history and the clinical findings of symmetrically distributed hyperpigmented macules and patches on the face. Examination under Wood's light was used when differentiating the pattern of pigment deposition (assessed by history and medical record) were selected. The cases being pregnant or nursing women, taking contraceptive pills at the time of study or past 12 months, any chronic illness, with allergy to any of the agents used in the treatment and those taking any topical and systemic treatment for melisma in the last one month were excluded from this study.

The cases were divided into two groups by simple random sampling method. MASI scoring done before starting the treatment. The cases in group A were treated by oral tranexamic acid ( $250 \mathrm{mg}$ twice daily); with topical $3 \%$ tranexamic acid solution (twice daily) and in group B with oral tranexamic acid (250 mg twice daily) with topical $20 \%$ azelaic acid (daily at night) for 6 months. Topical 3\% tranexamic acid solution was $3 \mathrm{~g}$ tranexamic acid dissolved in 10-cc ethanol $96^{\circ}, 10-\mathrm{cc} 1.3$-butanediol and distilled water up to 100 -cc formulated by Green Plus Pharma Lahore. Candidates were asked to apply sunscreen with SPF 60 or more during day time. They were followed every $2^{\text {nd }}$ month at OPD of dermatology and the final outcome was seen at 6 months where the efficacy was assessed on the basis of score on MASI scale. Follow-up done for 6 months after completion of treatment by using MASI score.

The data was entered and analysed by using (SPSS) version 23. Age was compared by using t-test. Qualitative variables were presented as frequencies and percentages, while quantitative variables as mean and standard deviation. Both the groups [Group A oral tranexamic acid (250mg twice daily) with topical 3\% tranexamic acid solution and Group B oral tranexamic acid (250 mg twice daily) with topical $20 \%$ azelaic acid] were compared in terms of efficacy by using Chi-square test taking $p$-value less than 0.05 as significant.

\section{RESULTS}

In the present study, there were a total of 100 cases, 50 in each group. Group A contained $6(12 \%)$ males and 44 $(88 \%)$ females, in contrast to group B, where they had 7 $(14 \%)$ males and $43(86 \%)$ females $(p=0.76)$. There was no significant difference in terms of mean MASI score at 2 and 4 months with $p$-value of 0.20 and 0.89 respectively.

However, mean MASI score was significantly less in group A where it was seen as $6.06 \pm 5.06$ as compared to $10.62 \pm 7.43$ in group $B$ with $p$-value of 0.001 as shown in Table I. There was also no significant difference of response of patients in terms of satisfaction (Table II) with $\mathrm{p}$-value of 0.74 . Pre-treatment mean MASI score in group $A$ was $33.7 \pm 12$ versus $34 \pm 13$ in group $B$ $(p=0.74)$. Mean age in group $A$ was $24 \pm 6.02$ and in group $B$ was $23.08 \pm 6.31(p=0.45)$.

Table I: Comparison of efficacy in both groups (independent t-test results).

\begin{tabular}{l|c|c|c}
\hline \multirow{2}{*}{ MASI score } & \multicolumn{2}{|c|}{ Treatment group } & \multirow{2}{*}{ Significance } \\
\cline { 2 - 3 } & Group A & Group B & \\
\hline At 2 months & $21.68 \pm 10.93$ & $24.32 \pm 9.82$ & 0.20 \\
At 4 months & $14.02 \pm 9.07$ & $17.04 \pm 8.47$ & 0.89 \\
At 6 months & $6.06 \pm 5.06$ & $10.62 \pm 7.43$ & 0.001 \\
\hline
\end{tabular}

Table II: Patient response to treatment in both groups (Chi-square test results).

\begin{tabular}{l|c|c|c}
\hline \multirow{2}{*}{ Response } & \multicolumn{2}{|c|}{ Treatment group } & \multirow{2}{*}{ Significance } \\
\cline { 2 - 3 } & Group A & Group B & \\
\hline Excellent & $14(28 \%)$ & $11(22 \%)$ & 0.74 \\
Good & $28(56 \%)$ & $29(58 \%)$ & \\
Fair & $8(16 \%)$ & $10(20 \%)$ & \\
\hline Total & 50 & 50 & \\
\hline
\end{tabular}

\section{DISCUSSION}

Melasma is defined as acquired macular hyper-pigmentation, commonly seen in young population and majority of them are females of child bearing age. ${ }^{14-18}$ Multiple factors that influence its presence and precipitation include oral contraceptive pills, pregnancy, genetics, endocrine dysfunction, nutritional deficiency, medications, hepatic dysfunction, and HIV etc. Sun exposure is common factor for exacerbation of symptoms. 19-22

In the present study, the efficacy in terms of MASI score was significantly better in group $A$ where it was seen as $6.06 \pm 5.06$ as compared to $10.62 \pm 7.43$ in group $B$ with $p$-value of 0.04 . No such comparison of this combination done before. However, significant difference in MASI score was not found at 2 and 4 months follow-up in this study.

In a study of 100 cases of melasma done by Lee et al. where they had used tranexamic acid intradermal every week for 12 weeks, found significant improvement in terms of MASI score at 8 and 12 weeks $(p<0.05) .15$ The efficacy seen in their study was even higher as compared to the present one, where it was seen in $76.5 \%$ of subjects. It may be due to the fact that they had longer follow-up as compared to current study. 
A study of 25 cases done by Fox et al., using tranexamic acid in the topical emulsion form up to 18 weeks, showed that the improvement was even better and was observed in $80 \%$ subjects, may be due to long follow-up. ${ }^{16}$ In both of these studies, no major side effects were observed.

Karn et al. compared the combination of oral tranexamic acid with topical hydroquinone with that of topical hydroquinone alone. ${ }^{17}$ It was observed that there was significant reduction in MASI score in tranexamic acid group. The efficacy of this can be explained by the factor that tranexamic acid is temperature-stable, not UV sensitive, and does not get oxidised easily. Thus, it acts as an ideal choice for composition in skin lightening creams. The advantage of it is that it is present in both oral as well as topical preparations.

Siddique et al. in their study used combination of $20 \%$ azelaic acid with $0.05 \%$ tretinoin. Good efficacy was seen in $38.66 \%$ of the cases only. Side effects were also noted during therapy. 18

Mazurek et al. also used different combinations of azelaic acid for the treatment of melasma, and they showed better efficacy but none was significantly better as compared to each other. The best results were seen in a combination of $20 \%$ azelaic acid and mandelic acid, phytic acid, 4N-butyl resorcinol, and ferulic acid. ${ }^{19}$ Fatemi et al. used topical solution form of tranexamic acid. That study introduced the topical TA as an effective and safe medication for the treatment of melasma. ${ }^{20}$

\section{CONCLUSION}

Combination of oral and topic 3\% tranexamic acid is significantly better than oral tranexamic acid with $20 \%$ azelaic acid for treatment of melasma.

\section{REFERENCES}

1. Pichardo $R$, Vallejos $Q$, Feldman $S R$, Schulz MR, Verma $A$, Sara $A$, et al. Arcury. The prevalence of melasma and its association with quality of life among adult male migrant latino workers. Int J Dermatol 2009; 48:22-6.

2. Handel AC, Miot LD, Miot HA. Melasma: a clinical and epidemiological review. An Bras Dermatol 2014; 89:771-82.

3. Ogbechie-Godec OA, Elbuluk N. Melasma: An up-to-date comprehensive review. Dermatol Ther (Heidelb) 2017; 7:305-18.

4. Rivas S, Pandya AG. Treatment of melasma with topical agents, peels and lasers: An evidence-based review. Am J Clin Dermatol 2013; 14:359-76.

5. Hexsel D, Lacerda DA, Cavalcante AS, Machado Filho CA, Kalil CL, Ayres EL et al. Epidemiology of melasma in Brazilian patients: A multicenter study. Int J Dermatol 2014; 53:440-4.
6. Kauh YC, Zachian TF. Melasma. Adv Exp Med Biol 1999; 455 : 491-9.

7. Estrada Castanon R, Andersson N, Hay R. Community dermatology and the management of skin diseases in developing countries. Trop Doct 1992; 22(Suppl1):3.

8. Passeron T. Melasma pathogenesis and influencing factors an overview of the latest research. J Eur Acad Dermatol Venereol 2013; 27(Suppl):5-6.

9. Grimes PE, Yamada N, Bhawan J. Light microscopic, immunohistochemical, and ultrastructural alterations in patients with melasma. Am J Dermatopathol 2005; 27:96-101.

10. Kang HY, Ortonne JP. What should be considered in treatment of melasma. Ann Dermatol 2010; 22:373-8.

11. Tan SK. Exogenous ochronosis in ethnic Chinese Asians: A clinicopathological study, diagnosis and treatment. J Eur Acad Dermatol Venereol 2011; 25:842-50.

12. Rendon M, Berneburg M, Arellano I, Picardo M. Treatment of melasma. J Am Acad Dermatol 2006; 54:S272-81.

13. Chan R, Park KC, Lee MH, Lee ES, Chang SE, Leow YH, et al. A randomized controlled trial of the efficacy and safety of a fixed triple combination (fluocinolone acetonide $0.01 \%$, hydroquinone $4 \%$, tretinoin $0.05 \%$ ) compared with hydroquinone $4 \%$ cream in Asian patients with moderate to severe melasma. Br J Dermatol 2008; 159:697-703.

14. Sheth VM, Pandya AG. Melasma: A comprehensive update: Part I. J Am Acad Dermatol 2011; 65:689-97.

15. Lee JH, Park JG, Lim SH, Kim JY, Ahn KY, Kim MY, et al. Localized intradermal microinjection of tranexemic acid for treatment of melasma in Asian patients: A preliminary clinical report. Dermatol Surg 2006; 32:626-31.

16. Fox C. From Tranexemic acid on freckles to non animal fillers: Patent, literature finding. Cosmetics and toiletries. Available at: http://www.cosmeticsandtoiletries.com [Accessed on February 5, 2018]

17. Karn D, Kc S, Amatya A, Razouria EA, Timalsina M. Oral tranexamic acid for the treatment of melasma. Kathmandu Univ Med J (KUMJ) 2012; 10:40-3.

18. Siddique MR, Khondker K, Hazra SC, Khan MSI. The efficacy of combination of $20 \%$ azelaid acid with $0.05 \%$ tretinoin cream in the treatment of melasma. J Pak Assoc Dematol 2011; 21:265-69.

19. Mazurek K, Pierzchala E. Comparison of efficacy of products containing azelainc acid in melasma treatment. $\mathrm{J}$ Cosmet Dermatol 2016; 15:269-82.

20. Ebrahimi B, Fatemi Naeini F. Topical trrnexamic acid as a promising treatment for melasma.J Res Med Sci 2014; 19:753-7.

21. Baliña LM, Graupe K. Treatment of melasma $20 \%$ azelaic acid versus 4\% hydroquinone cream. Int J Dermatol 1991; 30:893-5.

22. Sarah L. Sheu. Treatment of melasma using tranexamic acid. Cutis 2018; 101:E7-E8. 